International Conference on Renewable Energies and Power Quality (ICREPQ'11)

Las Palmas de Gran Canaria (Spain), 13th to 15th April, 2011

\title{
Induction Motor Capacitances Calculation Using FEA for Common Mode Current Studies in ATP
}

\author{
C. S. Chaves ${ }^{1}$, J. R. Camacho ${ }^{1}$, H. de Paula ${ }^{2}$, M. L. R. Chaves ${ }^{1}$ and E. Saraiva ${ }^{1}$ \\ ${ }^{1}$ Electromagnetic Transients Laboratory - School of Electrical Engineering \\ Universidade Federal de Uberlândia - UFU \\ UFU/Campus Santa Mônica - Av. João naves de Ávila 2121 - CEP 38400-299 - Uberlândia, MG - Brazil \\ e-mail: kmillachaves@yahoo.com.br,jrcamacho@ufu.br \\ ${ }^{2}$ Industrial Applications Laboratory - Universidade Federal de Minas Gerais - UFMG \\ Av. Antônio Carlos, 6627 - Pampulha/CEP 31270-901 - Belo Horizonte, MG - Brazil \\ e-mail: helder@cpdee.ufmg.br
}

\begin{abstract}
The prediction of common-mode currents in inverter-driven induction motors is necessary to propose mitigating solutions in order to prevent failures and ensure the proper operation of the entire electrical system. The motor model for these high-frequency studies is relatively simple; however, to find its parameters accurately is a very complex task. In this context, this paper presents an alternative to estimate leakage capacitances in induction motors, based on the finite element technique, through computational simulation using FEMM (Finite Element Methods Magnetics). Then, an application of the motor capacitances in an appropriate model for common-mode quantities determination is shown as an example, using the ATP (Alternative Transients Program).
\end{abstract}

\section{Key words}

ATP, common-mode currents, FEMM, high-frequency induction motor model, leakage capacitance calculation.

\section{Introduction}

The power quality is a subject that does not only consider the standard waveforms of the supplied voltage, but also the good performance of electrical machines. These are always being analyzed due to their great relevance and contribution to the electrical system. The study of side effects of the joint operation between induction motors and inverters, aiming to improve the system performance, efficiency and control, is necessary to prevent the decrease of the motor lifetime and also for protection equipment specification and EMC issues.

Regarding three-phase PWM inverters, it is well known that the instantaneous combination of its output phase voltages is a non-zero value. This resulting voltage is characterized by a step waveform, which variations $(\mathrm{dv} / \mathrm{dt})$ correspond to one third of the DC link voltage of the converter. Each variation of this common-mode voltage excites the capacitive couplings between connecting cables, converter and motor to the ground, providing the circulation of common-mode currents [1]. These currents are responsible for the improper operation of fault-to-ground relays, electromagnetic interference (EMI) and bearing failures, among other problems [2, 3].

Concerning the motor, its model for the study of these high-frequency phenomena is based on an equivalent electrical circuit [4], where its internal capacitive couplings are included, such as the ones between stator windings and frame $\left(\mathrm{C}_{\mathrm{sf}}\right)$, stator windings and rotor $\left(\mathrm{C}_{\mathrm{sr}}\right)$, rotor and frame $\left(\mathrm{C}_{\mathrm{rf}}\right)$ and bearings $\left(\mathrm{C}_{\mathrm{b}}\right)$. For the capacitances $\mathrm{C}_{\mathrm{sf}}$ and $\mathrm{C}_{\mathrm{rf}}$, displacement currents are established for each variation of the common-mode voltage. Through the bearings, discharge currents are generated whenever the induced electrostatic voltage on the machine shaft is high enough to disrupt the dielectric rigidity of the lubricant grease. Its effect is to damage the bearing balls and races, taking it to premature failure $[3$, 4].

Despite the simplicity of the motor equivalent circuit including its capacitances, the determination of these parameters shows to be a complex task. Measurements require expensive instruments and implicate in practical difficulties [5], which turn the procedure into something generally impracticable. On the other hand, analytical formulation $[5,6]$ does not provide accurate results, since several simplifications are made in its derivation.

In this context, this paper presents an interesting alternative, based in the Finite Element Method, to calculate the capacitances $\mathrm{C}_{\mathrm{sf}}, \mathrm{C}_{\mathrm{sr}}$ and $\mathrm{C}_{\mathrm{rf}}$ through the software FEMM (Finite Element Methods Magnetics). In sequence, the application of such capacitance values in 
the motor equivalent circuit is done in ATP (Alternative Transients Program), for the analysis of the commonmode high frequency phenomena under study.

\section{Simulations in FEMM and Capacitance Determination}

In this research, a 4 pole / $220 \mathrm{~V} / 3 \mathrm{HP}$ induction motor was used. The capacitances $\mathrm{C}_{\mathrm{sf}}, \mathrm{C}_{\mathrm{sr}}$ and $\mathrm{C}_{\mathrm{rf}}$ prediction in FEMM was made based on a detailed representation of the motor in two dimensions, taking into account all the relevant material properties (dielectric constants and design details) for this calculation. Figure 1 shows the representation created in FEMM of one of the motor parts.

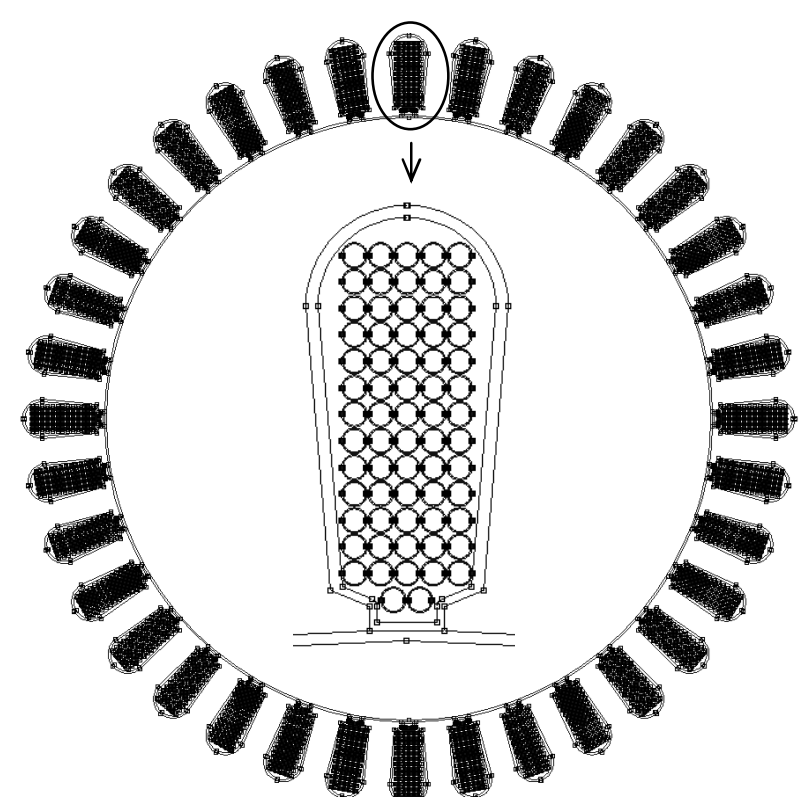

Fig. 1. 2D motor representation in FEMM - front view without covers. Detail showing the slots and air gap.

In the complete motor representation, it was considered the rotor, magnetic core and windings of the stator (including the coil head), frame and materials responsible for the wire insulation, such as the varnish and insulating film. However, when it comes to the rotor, bearings and frame, only their surfaces were considered in the representation, since the entire structure of these components is not relevant to determine the capacitances analyzed in this research.

\section{A. Capacitance between Stator and Frame $-C_{s f}$}

The capacitance $\mathrm{C}_{\mathrm{sf}}$ was obtained in FEMM after the simulation of the electric field propagation and equipotential surfaces distribution in the motor, taking into account the stator windings energized and the frame grounded. In this simulation, the rotor was disregarded. The obtained results in the simulations were then compared with measurements taken in the motor used in the research.

The capacitance measurements were performed with the instrument Minipa Digital MC - $152(200 \mathrm{pF}$ - 20000 $\mu \mathrm{F})$. With the rotor locked and frame grounded, the equivalent capacitance was measured by the stator terminals, which were interconnected at a common point. This capacitance represents a parallel association between $\mathrm{C}_{\mathrm{sf}}$ and $\mathrm{C}_{\mathrm{sr}}$. To measure $\mathrm{C}_{\mathrm{sf}}$ separately, the rotor had to be removed from the motor. As a consequence, the rotor was disregarded from the simulations. Nevertheless, the results of measurements in both cases (motor with and without the rotor) were almost the same, showing that $\mathrm{C}_{\mathrm{sf}}$ is much greater than $\mathrm{C}_{\mathrm{sr}}$. Figure 2 illustrates the close proximity between the capacitance $\mathrm{C}_{\mathrm{sf}}$ obtained through the simulations and the average of measurements taken, showing the reliability of the methodolgy proposed here.

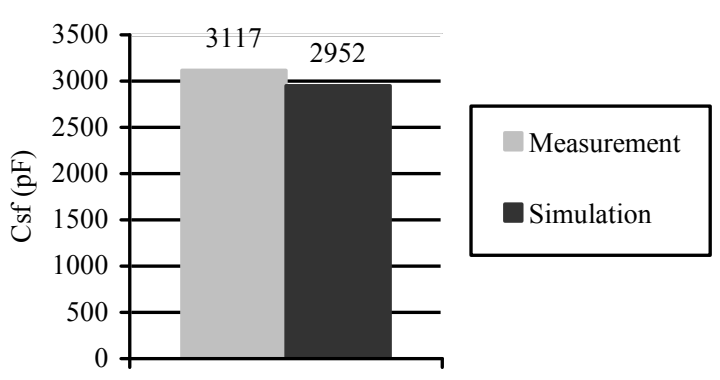

Fig. 2. Obtained values through simulations and measurements for the capacitance $\mathrm{C}_{\mathrm{sf}}$.

It was also noticed on simulations that most of the electrostatic energy stored regarding $\mathrm{C}_{\mathrm{sf}}$ comes from the stator magnetic region. So, it is possible to discard the coil head from the motor representation, without substantial difference in results.

\section{B. Capacitance between Stator and Rotor $-C_{s r}$}

To obtain $\mathrm{C}_{\mathrm{sr}}$ from measurements, the subtraction between the two values found in the measurements mentioned previously must be made, because this difference is precisely the capacitance $\mathrm{C}_{\mathrm{sr}}$. However, as it was mentioned before, the measurement results considering the motor with and without the rotor were nearly the same. Thus, $\mathrm{C}_{\mathrm{sr}}$ cannot be obtained through conventional methods of measurement, since it involves a subtraction between two values much larger than the expected result, which leads to dubious values. Moreover, the limitations of the measuring instrument concerning its accuracy must be considered because, in this situation, they also interfere considerably on the results. The calculation of $\mathrm{C}_{\mathrm{sr}}$ in FEMM involves this same subtraction, but the result is more reliable since the precision due to the finite element method is greater than that obtained by the measuring instrument.

In order to have a reference value and be able to compare the simulation results in FEMM, the formulation proposed in [6] was used to calculate $\mathrm{C}_{\mathrm{sr}}$ analytically. The value found through the formula was $67.41 \mathrm{pF}$, while in simulations the obtained value was $77.58 \mathrm{pF}$. It was observed from simulations that the coil head region was the place where it was obtained the biggest difference between the results. This indicates that most of the stored electrostatic energy due to $\mathrm{C}_{\mathrm{sr}}$ comes from this area. In spite of the previous situation, the representation of the 
coil head in this case is important and cannot be disregarded. On the other hand, the motor representation can be simplified by neglecting the stator magnetic region.

\section{Capacitance between Rotor and Frame $-C_{r f}$}

As shown so far, the FEMM simulations reproduce the measurement methods done in the motor. To measure $\mathrm{C}_{\mathrm{rf}}$, it is necessary to ground the frame and connect the rotor to a drive motor, so the motor could move without applying voltage in stator windings [5]. This sometimes allows the formation of a lubricant film between bearing balls and races, and that forms a capacitor called $\mathrm{C}_{\mathrm{b}}$. For that reason, the capacitance measured in this test is equal to an association between all leakage capacitances of the motor, and thus $\mathrm{C}_{\mathrm{rf}}$ can be obtained by the equation (1).

$$
C_{e q}=\left(\frac{1}{C_{s f}}+\frac{1}{C_{s r}}\right)^{-1}+C_{r f}+C_{b}
$$

The estimation of $\mathrm{C}_{\mathrm{rf}}$ from FEMM simulations aimed to determine this capacitance directly, without the need of (1). It is known that $C_{b}$ varies with the motor rotation speed $[3,5,6]$, so its measure is uncertain. This was one of the reasons that made impossible the measurement of $\mathrm{C}_{\mathrm{rf}}$ in the case of the present work, and then the simulation result was compared again with the value obtained by the analytical formulas proposed in [6]. Using the equation, the value found for $C_{\mathrm{rf}}$ was 936.15 $\mathrm{pF}$, while the result from the simulation was equal to $860.93 \mathrm{pF}$. In the simulations, it could be observed that most of the stored energy associated to the $\mathrm{C}_{\mathrm{rf}}$ also comes from the stator magnetic region, since it is the area where the rotor is closest to the ground. Consequently, in this case the coil head could also be neglected to simplify the representation and speed up the simulation.

\section{Motor Equivalent Circuit and Electrical System Characteristics to Study the Common Mode Currents}

The motor equivalent circuit for high-frequency studies is already well known. Even with some variations among the proposals [4, 5, 7], a basic structure is always maintained. This research uses the equivalent circuit proposed in [4] and has most of the required parameters. So, simulations in ATP were made to verify the behavior of common-mode currents in the motor.

\section{A. Motor Characteristics and Its Equivalent Circuit}

The bearing in the front part of the motor is type $6205 \mathrm{ZZ}$ and in the back part is $6204 \mathrm{ZZ}$, which are made of metallic spheres and grease for lubrication and insulation. According to [5], the grease used in bearings has a dielectric strength around 1 and $30 \mathrm{kV} / \mathrm{mm}$, and the thickness of the lubricant film formed between the spheres and tracks, when the motor is running, varies between 0.2 and 2 micrometers. From this information, it was supposed that the bearing grease has a dielectric strength equal to $15 \mathrm{kV} / \mathrm{mm}$. And so, for a lubricant film thickness of $1 \mu \mathrm{m}$ between the balls and races, the dielectric breakdown voltage is equal to $15 \mathrm{~V}$.

The motor capacitive paths for the common-mode currents are illustrated in Fig. 3, while the corresponding equivalent circuit is shown in Fig. 4.

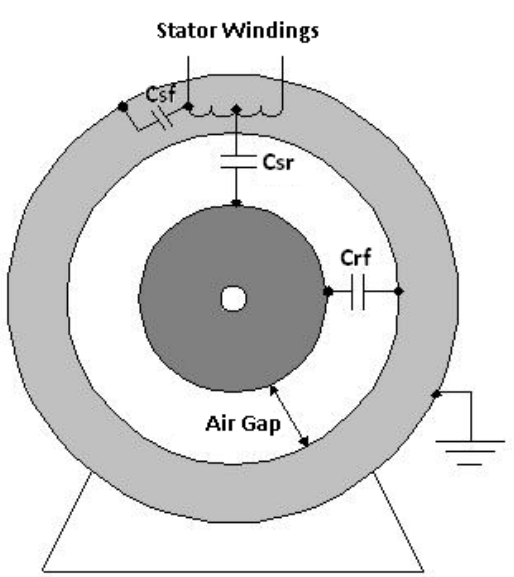

Fig. 3. Capacitive paths of the motor for the common-mode currents.

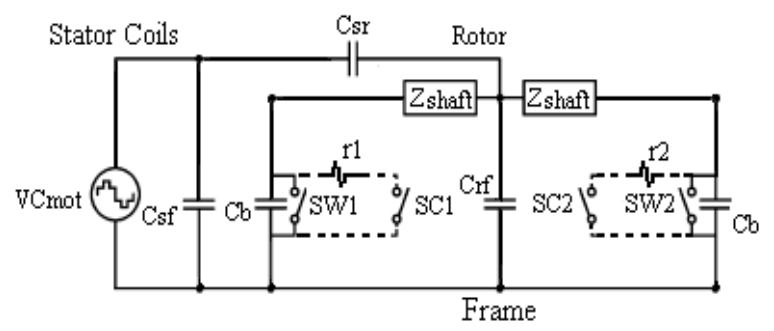

Fig. 4. Common-mode current equivalent circuit of the motor [4].

Where $C_{b}$ is the bearing capacitance and $Z_{\text {shaft }}$ is the halfimpedance of the motor shaft. The source $V_{\text {Cmot }}$ represents the inverter, which supplies the motor with common-mode voltage, while the switches SW1 and SW2 are used to represent the occurrence of dielectric breakdown in the bearings. The opened switches indicate the sustenance of the insulation, while the closed switches represent the grease dielectric breakdown. There are nonlinear resistances in series with the switches SW1 and SW2 that could be ignored in the model as they do not offer any contribution to the investigation of the circulating current. When the rotor is not moving, the bearing spheres are generally in contact with the races, having a resistive characteristic. Bearings become capacitive during the rotor operation, when it is created a grease film between balls and tracks. In order to reproduce this phenomenon, the switches $\mathrm{SC} 1$ and $\mathrm{SC} 2$ were inserted in the equivalent circuit to control the behavior of $\mathrm{C}_{\mathrm{b}}$. When these switches are closed, the balls are in metallic contact with the races, creating a resistive path for common-mode currents through the resistors $\mathrm{r} 1$ and $\mathrm{r} 2$. When they are opened, the capacitive circuit takes place. The dielectric breakdown in the bearings provides a path to $C_{b}$ discharge through the shaft impedance [4], and it forms two loops for the current circulation, as follows: 
Loop 1: $\mathrm{C}_{\mathrm{rf}} \rightarrow \mathrm{Z}_{\text {shaft }} \rightarrow \mathrm{C}_{\mathrm{b}} \rightarrow$ Frame $\rightarrow \mathrm{C}_{\mathrm{rf}}$

Loop 2: $\mathrm{C}_{\mathrm{b}} \rightarrow 2 \cdot \mathrm{Z}_{\text {shaft }} \rightarrow \mathrm{C}_{\mathrm{b}} \rightarrow$ Frame $\rightarrow \mathrm{C}_{\mathrm{b}}$

There is a difference between the bearings from the front and back of the motor, thus leading to different dielectric breakdown characteristics in each bearing [4]. Since the one in the back is smaller, its lubricant film thickness might be thinner and, consequently, the capacitance is larger. Thus, the breakdown voltage is slightly lower in the back bearing and the dielectric rupture occurs first. In this study, it was supposed that the capacitances and breakdown voltages of the bearings were the same, because the difference between them is more relevant in studies of shaft end-to-end voltage, which does not correspond to the present case. Moreover, it was admitted to these parameters typical values mentioned in other studies [5], due to the lack of specific information and measurement difficulties. Table I shows the necessary input data for the motor equivalent circuit elaboration.

Table I - Induction Motor Model Parameters

\begin{tabular}{|c|c|}
\hline \multicolumn{2}{|c|}{ INDUCTION MOTOR -3 HP/4 POLES } \\
\hline $\mathrm{C}_{\mathrm{sf}}(\mathrm{pF})$ & 2951.72 \\
\hline $\mathrm{C}_{\mathrm{sr}}(\mathrm{pF})$ & 77.58 \\
\hline $\mathrm{C}_{\mathrm{rf}}(\mathrm{pF})$ & 860.933 \\
\hline $\mathrm{C}_{\mathrm{b}}(\mathrm{pF})$ & 350 \\
\hline $\mathrm{L}_{\text {shaft }}(\mu \mathrm{H})$ & 8 \\
\hline $\mathrm{R}_{\text {shaft }}(\mathrm{m} \Omega)$ & 54 \\
\hline $\mathrm{V}_{\text {breakdown }}$ & $15 \mathrm{kV} / \mathrm{mm}$ \\
\hline
\end{tabular}

B. Characteristics of the Interconnection Cables and Common Mode Voltage Source

The source of common-mode voltage and the inverter-tomotor connecting cable were represented in the simulations using existing models [1]. The cable model includes skin effect accurate representation up to the $\mathrm{MHz}$ range (for the conductors and for the ground impedance as well) and also the distributed nature of its parameters. The cable has a $4 \mathrm{~mm}^{2}$ cross section, triangular geometry and a length of 20 meters.

The common-mode voltage waveform was obtained from the combination of phase-trapezoidal pulses with $300 \mathrm{~V}$ and rise time of $100 \mathrm{~ns}$; in this way, the common-mode voltage steps applied to the motor and cable capacitances to the ground is $100 \mathrm{~V}$. Since this cable model reproduces the pulses propagation and reflection phenomena (for both differential and common modes), it is possible to observe the common-mode voltage oscillations at the motor terminals and to accurately obtain the transient common-mode currents under study.

\section{Simulations in ATP and Results}

The simulation in ATP was performed considering an integration time step equal to $10^{-9}$ seconds. The motor common-mode motor input voltage, shaft voltage and the common-mode currents (the total common-mode current and the portion that circulates through the bearings) were analyzed. The following figures illustrate the simulation results.

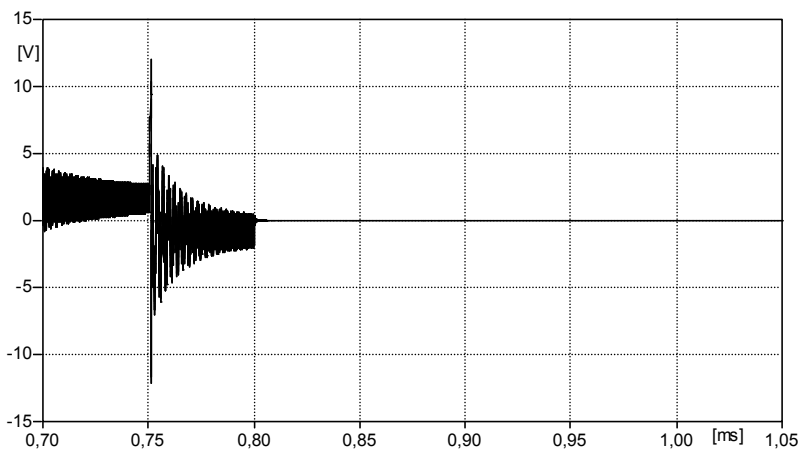

Fig. 5. Common-mode voltage at the bearings.

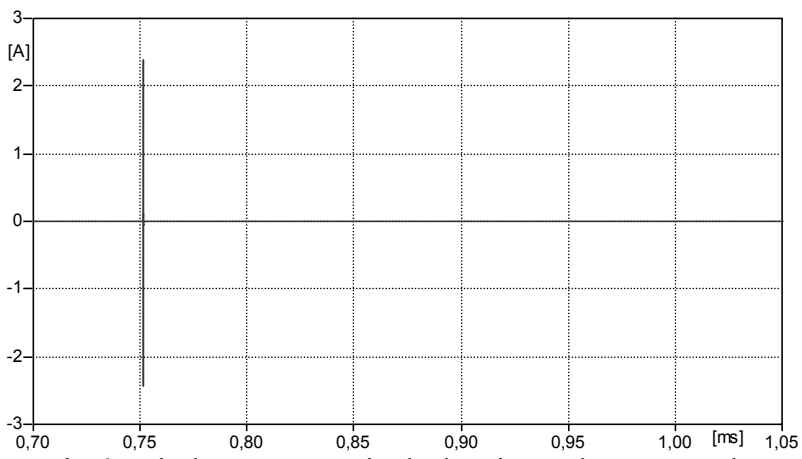

Fig 6. Discharge current in the bearings when occurs the dielectric breakdown.

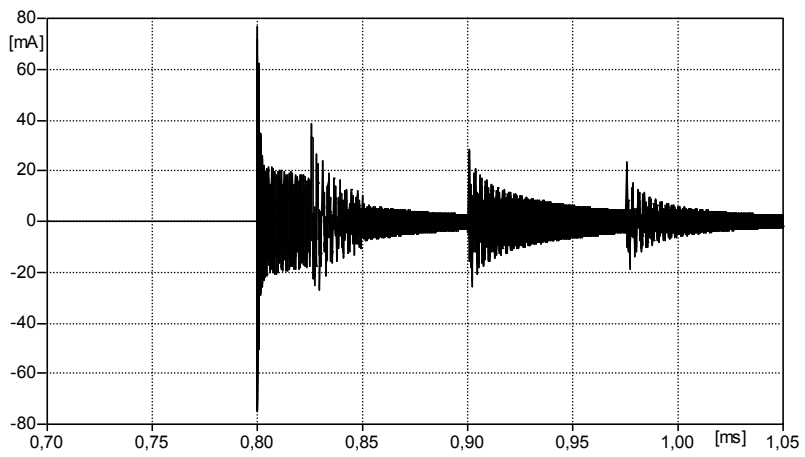

Fig 7. Discharge current in the bearings when occurs the contact between balls and bearing trails.

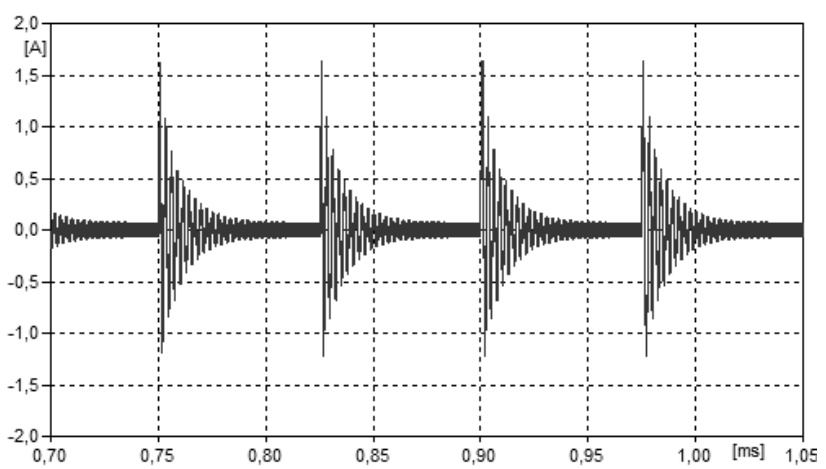

Fig. 8. Total common-mode current to the ground.

In the results, it could be seen that the discharge currents did not influence the total common-mode current as it does not depend on these parcels. It was verified that the bearings entered in contact with the trails when the time was $0.8 \mathrm{~ms}$, and after that the voltage shaft felt down to zero because it was grounded by the bearing balls. The moment of the grease film creation and when the balls touch the trails, its duration and the number of times that 
these events occur are random; it is observed from measurements that they can happen anytime and have any duration. The discharge current values exceeded $2 \mathrm{~A}$ and it is much larger than the one due to the bearing contact. Therefore, it is observed that the discharge current from the dielectric breakdown might cause more damage to bearings because they are greater than the one from the balls contact. Moreover, the use of inverters without preventive action can lead to premature bearing failures in induction motors, reducing their lifetime. The distortions in the common-mode voltage waveforms not only illustrate the effect of voltage reflection due the interconnecting cables, but also the switching events of the source.

The results are in conformity with the expectations; then, the entered values for leakage capacitances in the motor equivalent circuit were reasonable to analyze the dielectric breakdown and balls contact with trails event in the bearings, and the magnitude of common-mode currents.

\section{Conclusions}

It was verified during the research that it is not feasible the exact representation of all the details and elements of the motor. The reason of this difficulty is the lack of information and some constructive detail imprecision. Motors of the same manufacturing line and rated power may have some constructive differences and, consequently, slightly different leakage capacitances. Though, it was possible to obtain suitable results from the proposed systematic. Moreover, among the parameters considered, the one that most affected the calculated capacitances was the distance between the excited conductor (the stator windings or rotor) and the grounded region (frame or rotor). The dielectric constant values of the insulation materials impacted the capacitances final values much less than expected, showing that the use of typical values is reasonable in the lack of more accurate or specific information.

The study performed in ATP demonstrated that PWM inverters not only degrade the electrical power quality, but also the brings undesired high-frequency phenomena to the driven motor. Thus, the concern related to the effects of common-mode currents in the drive system is justified; the present study aimed to determine the motor capacitances to make possible the determination of such currents. The software FEMM is very efficient on estimating those capacitances, providing more benefits than other methods. This can be justified by the fact that it is more accurate than the analytical formulations and simpler than the measurement process.

Making a comparison between some alternatives for the determination of the motor leakage capacitances, the following findings can be emphasized:

1) Motor constructive details. Either the simulations (which uses the finite element method) or analytical formulations require their previous knowledge.
2) Simplifications. The analytical formulations provide greater simplifications which can compromise results in some cases.

3) Measurement effectiveness. By the traditional measurement methods, it is possible to obtain the equivalent leakage capacitance of the motor. However, more complex/not feasilble practical procedures are required to measure each capacitance separately.

Based on these observations, it can be concluded that the described measurement techniques are not always practical and the analytical formulations involve more simplifying considerations than the computer simulations; in this way, it can be stated that the the proposed methodology arises as an attractive tool for the motor capacitances determination.

\section{Acknowledgements}

Our thanks to Hugo Gustavo Gomes and Eribert Augusto Neves (WEG Motores) and MEC/CAPES, for the invaluable collaboration and financial support.

\section{References}

[1] H. de Paula, D. A. Andrade, M. L. Chaves, J. L. Domingos, M. A. A. Freitas, "Methodology for Cable Modeling and Simulation for High-Frequency Phenomena Studies in PWM Motor Drives", IEEE Trans. on Power Electronics, pp. $744-752$, March 2008 .

[2] A. V. Jouanne et al.., "An Evaluation of Mitigation Techniques for Bearing Currents, EMI and Overvoltages in ASD Applications", IEEE Trans. on Industry Applications, vol. 34, n. 5, pp. 1113-1122, 1998.

[3] J. M. Erdman, R. J. Kerkman, D. W. Schelegel, G. L. Skibinski, "Effect of PWM Inverters on AC Motors Bearing Currents and Shaft Voltages", IEEE Trans. on Industry Applications, vol. 32, n. 2, March/April 1996.

[4] U. T. Shami, H. Akagi, "Experimental Discussions on a Shaft End-to-End Voltage Appearing in an InverterDriven Motor", IEEE Trans. on Power Electronics, vol. $24, n^{\circ} .6$, June 2009.

[5] J. Erdman et al.., "System Electrical Parameters And Their Effects On Bearing Currents", IEEE APEC Conference, San Jose, CA, 1996.

[6] A. Muetze, A. Binder, "Calculation of Motor Capacitances for Prediction of the Voltage Across the Bearings in Machines of Inverter-Based Drive Systems," IEEE Trans. Ind. Appl., vol.43, $\mathrm{n}^{\mathrm{o}} .3$ (2007) pp.665-672.

[7] R. R. Riehl, E. R. Filho, "High Frequency Capacitances Determination in Three-Phase PWM Inverter-Motor Drive System Using an Alternative Method Applied to EMI Effect Studies", 9th COBEP, pp.137 - 141, 2007.

[8] T. Humiston, "Parameter Measurements to Study Surge Propagation in Induction Machines". IEEE Transactions on Industry Applications, vol.40, no.5 (2004), pp. 1341 1348.

[9] K. Maki, H. Funato, L. Shao, "Motor Modeling for EMC simulation by 3-D Electromagnetic Field Analysis". IEEE International IEMDC '09, Miami, FL, jun 2009. 